\section{Beta-Cell Imaging: Opportunities and Limitations}

TO THE EDITOR: We read with interest the review by Ichise and Harris (1), who proposed ${ }^{11} \mathrm{C}$-dihydrotetrabenazine $\left({ }^{11} \mathrm{C}\right.$ DTBZ) PET as a potentially useful method for imaging $\beta$-cells in the native pancreas. ${ }^{11} \mathrm{C}$-DTBZ targets the vesicular monoamine transporter type 2 , which is expressed by $\beta$-cells but is absent from the exocrine pancreas. Although the authors have discussed several limitations of this method, they have not addressed the one that is perhaps most important and precludes the use of ${ }^{11} \mathrm{C}$ DTBZ PET for imaging $\beta$-cells in the native pancreas. $\beta$-cells represent only $1 \%-2 \%$ of pancreatic volume and are clustered in islets of Langerhans throughout the pancreas. Islets are very small ( $\sim 50-400 \mu \mathrm{m}$ in diameter (2)) - a problem that cannot be resolved by current noninvasive in vivo imaging methods, including PET. Equally important, the islets and pancreas of patients with diabetes are atrophic, compared with those of healthy controls (2). The combination of the relatively low spatial resolution of PET and islet/pancreas atrophy in diabetes will result in underestimation of the true concentration of a certain compound (in this case ${ }^{11} \mathrm{C}$-DTBZ), if not corrected for partialvolume effects $(3,4)$. In fact, if one corrects for partial-volume effects, there will be no differences in degree of uptake of a certain $\beta$-cell-specific tracer between patients (with a substantial degree of atrophy) and controls.

Sweet et al. (5) reported that the low-volume fraction of $\beta$-cells within the exocrine pancreas (about 1:100) requires that $\beta$-cells retain labeled imaging agents at least 1,000-fold more strongly than exocrine cells, in order for $\beta$-cell imaging in the pancreas to succeed by quantitative techniques. However, this level of retention is almost impossible and is not achievable with any existing agents. In addition, the high concentration of such compounds will result in significant radiation toxicity to the $\beta$-cells. Therefore, we believe it is ill conceived that $\beta$-cell imaging in the native pancreas be considered feasible with the technologies available today. However, the contrary is true for imaging the fate of transplanted pancreatic islets. Particularly, subcutaneous islet transplants may be reasonable, quantifiable targets for PET. The advantage of transplanting islets subcutaneously is that this site suffers considerably less from accumulation and uptake of certain compounds in non- $\beta$-cells than do other organs or structures, such as the liver and kidneys. The high concentration of $\beta$-cells at a known location and the opportunity to perform partial-volume correction of acquired PET data $(3,4)$ make it possible to calculate the exact standardized uptake value at this site.

Besides radiolabeled DTBZ, which was discussed by Ichise and Harris (1), other promising PET radiotracers for $\beta$-cell imaging, including ${ }^{18} \mathrm{~F}$-L-dihydroxyphenaline (6) and sulfonylurea receptor ligands (7), deserve further investigation. We foresee an important role for ${ }^{18} \mathrm{~F}$-FDG in the evaluation of islet transplants, complementary to $\beta$-cell-specific tracers $(8) .{ }^{18}$ F-FDG may be used as a tracer to image immune activation associated with the rejection of islet grafts in the subcutaneous space (8). Early detection of subcutaneous islet cell rejection by increased trapping of ${ }^{18} \mathrm{~F}-\mathrm{FDG}$

COPYRIGHT @ 2011 by the Society of Nuclear Medicine, Inc. and decreased trapping of $\beta$-cell-specific tracers (which are taken up only by functioning islets) leads to a window for potential intervention before frank biochemical failure and rescue of the subcutaneous islet graft.

We hope that this communication will eliminate some important misconceptions about $\beta$-cell imaging and stimulate meaningful investigations in this increasingly important field.

\section{REFERENCES}

1. Ichise M, Harris PE. Imaging of $\beta$-cell mass and function. J Nucl Med. 2010; 51:1001-1004.

2. Katsumichi I, Pour PM. Diabetes mellitus in pancreatic cancer: is it a causal relationship? Am J Surg. 2007;194(4, suppl)S71-S75.

3. Hickeson M, Yun M, Matthies A, et al. Use of a corrected standardized uptake value based on the lesion size on CT permits accurate characterization of lung nodules on FDG-PET. Eur J Nucl Med Mol Imaging. 2002;29:1639-1647.

4. Basu S, Zaidi H, Houseni M, et al. Novel quantitative techniques for assessing regional and global function and structure based on modern imaging modalities: implications for normal variation, aging and diseased states. Semin Nucl Med. 2007;37:223-239.

5. Sweet IR, Cook DL, Lernmark A, Greenbaum CJ, Krohn KA. Non-invasive imaging of beta cell mass: a quantitative analysis. Diabetes Technol Ther. 2004;6:652-659.

6. Hardy OT, Hernandez-Pampaloni M, Saffer JR, et al. Accuracy of $\left[{ }^{18} \mathrm{~F}\right]$ fluorodopa positron emission tomography for diagnosing and localizing focal congenital hyperinsulinism. J Clin Endocrinol Metab. 2007;92:4706-4711.

7. Schneider S, Feilen PJ, Schreckenberger M, et al. In vitro and in vivo evaluation of novel glibenclamide derivatives as imaging agents for the non-invasive assessment of the pancreatic islet cell mass in animals and humans. Exp Clin Endocrinol Diabetes. 2005;113:388-395.

8. Kalliokoski T, Simell O, Haaparanta M, et al. An autoradiographic study of $\left[{ }^{18} \mathrm{~F}\right]$ FDG uptake to islets of Langerhans in NOD mouse. Diabetes Res Clin Pract. 2005;70:217-224.

\section{Thomas C. Kwee \\ Sandip Basu \\ Babak Saboury \\ Drew A. Torigian \\ Ali Naji}

Abass Alavi*

*Hospital of the University of Pennsylvania

3400 Spruce St., 110 Donner Bldg.

Philadelphia, PA 19104

E-mail: abass.alavi@uphs.upenn.edu

DOI: 10.2967/jnumed.110.085530

REPLY: We would like to thank Dr. Kwee et al. for their interest and comments about our review on PET imaging of $\beta$-cell mass (1). They raise a major concern that PET with its limited spatial resolution may not be able to resolve small islets containing $\beta$ cells that are scattered throughout the pancreas. To address this concern, we would like to point out first that the ultimate goal of PET using radioligands such as ${ }^{11} \mathrm{C}$-dihydrotetrabenazine $\left({ }^{11} \mathrm{C}\right.$ DTBZ) that target transporters and receptor proteins is to estimate average target protein density per unit volume of the tissue (pancreas) in which the target proteins are found ( $B_{\text {avail }}$, in units of 